\title{
IMPROVING PRINTING AND WRITING PAPER PROPERTIES BY COATING WITH NANOCLAY MONTMORILLONITE (K10)
}

\author{
HUSHANG GHANBARI, JAFAR EBRAHIMPOUR KASMANI* and AHMAD SAMARIHA*** \\ "Department of Wood and Paper Engineering, Savadkooh Branch, Islamic Azad University, Savadkooh, Iran \\ ${ }^{* *}$ Young Researchers and Elites Club, Science and Research Branch, Islamic Azad University, \\ Tehran, Iran \\ \Corresponding author: Jafar EbrahimpourKasmani, Jafar_kasmani@yahoo.com
}

Received June 14, 2018

\begin{abstract}
The present study aimed to improve the surface features of mechanical printing paper manufactured by the Mazandaran Wood and Paper Company. Inorganic materials, including nanoclay (in 6 different amounts) were used in different weight percentages of latex and applied by the blade coating method. Structural studies, such as SEM and XRD, were performed, and the mechanical and optical properties of the paper samples were evaluated. Scanning electron microscopy showed that the coverage achieved with the method used was relatively good. X-ray diffraction analysis indicated that an intercalation structure was formed. Moreover, the results of the mechanical tests showed that the enhancement of the nanoclay amount up to $25 \%$ can increase the air resistance, opacity and yellowness of the samples by $423.6,4.1$ and $59.5 \%$, respectively, while decreasing their tensile strength, tear resistance, burst strength, stiffness, softness and brightness by 12.2, 12, 5.5, 6.5, 2.2 and 13.4\%, respectively, in comparison with the values recorded for the control samples.
\end{abstract}

Keywords: nanoclay, paper mechanical properties, optical features, coating, XRD, SEM

\section{INTRODUCTION}

Paper coating can improve surface softness significantly by filling the cavities and the empty spaces between the fibers. In addition, an enhancement in gloss, opacity and surface resistance of the coated paper is expected, along with a reduction of ink absorption and mechanical properties. The most important result of coating paper consists in improving the printability properties. Various coating layers should strengthen the paper against the pressure of printing. For example, due to the stickiness of offset printing ink, paper coating resistance against dislodging or pick strength should be sufficient in the thickness direction (Z). ${ }^{1}$

Extensive researches have been done in the field of nanoparticles, due to their great potential applications in many industries. ${ }^{2}$ Today, among various fillers consisting in nanoscale particles, nanoclay particles have drawn attention since they have the ability to form different structures (intercalated, intercalated-flocculated, exfoliated), consequently imparting different features to the end products. ${ }^{3-6}$ Usually, different kinds of clays and precipitated calcium carbonate (PCC) are used as coating pigments for printing and writing paper to improve its printing properties. These pigments have high reflection in the visible wavelength range, superior clarity and refractive index, as well as good compatibility with other compounds that are used in coating papers. Silica and precipitated calcium carbonate have high porosity and may help establish strong interactions with the cellulose fibers of the paper. $^{7-11}$ Montmorillonite is one of the most important clay minerals used in polymer processing, it shows unique mechanical properties and is applied as nano-filler in the production of nano-composites. ${ }^{12}$ Inherent differences in the shape of the filler particles have impact on the reflection of light on the surface of coated paper. Thus, nanoclay has a higher light diffusion coefficient due to its higher specific surface area and better surface uniformity, which improves the printing quality.

Therefore, this study is an attempt to improve the optical and printability properties of paper, while maintaining its strength, by applying different coating formulations. The mechanical 
papers manufactured by the Mazandaran Wood and Paper Company present a yellowing phenomenon over time, due to the presence of modified lignin. If paper coating can delay the onset of yellowing and the effects of light exposure, the coating will be considered efficient. Other research has shown that the use of nanoclay decreased yellowness and may increase the time that takes a paper to turn yellow. A comparison between other optical features of papers, such as opacity and brightness, indicated marginal differences between papers. It is obvious that, if an enhancement of brightness is necessary, polymer materials with higher brightness and up to $10 \%$ titanium dioxide can be used in the coating formulation. ${ }^{1}$ The use of precipitated calcium carbonate (PCC) and ground calcium carbonate (GCC) in coating formulations, in amounts of 14 grams per square meter, to treat the surface of cardboards showed that the highest surface brightness was imparted by particles with narrow particle size distribution, while the addition of latex to the coating formulation can decrease gloss by enhancing roughness. Furthermore, the addition of higher amounts of latex reduced porosity and therefore caused light scattering. ${ }^{13-14}$

Previous investigations of the mechanical properties of coated paper indicated that, except stiffness, there are no significant changes in comparison with the control samples. ${ }^{14}$
Also, the findings indicated that the surface of nanoclay coated paper was uniform and smooth, due to the high specific surface area of the nanoclay and the plate-like shape of its particles. ${ }^{14}$ This study aimed to assess the mechanical and optical properties of printing papers treated by coating formulations comprising a nanoclay mineral and latex.

\section{EXPERIMENTAL}

\section{Materials}

Paper

Mechanical printing paper made from chemimechanical pulp (CMP), with the basic weight of 70 $\mathrm{g} / \mathrm{m}^{2}$, was obtained from Mazandaran Wood and Paper Co. The base paper was produced from hardwood, with the following specifications: $7.5 \%$ moisture, $78 \%$ brightness, $86 \%$ opacity, $10 \%$ ash and $1.5 \mathrm{~g} / \mathrm{m}^{2}$ starch.

\section{Nanoclay}

Nanoclay produced by Sigma-Aldrich under the trade name of Montmorillonite K10 was used. Its specifications are provided in Table 1.

\section{Acrylamide}

Acrylamide latex (SH-315) was purchased from Simab Resin Co. It had a milky appearance with an anionic emulsion system, 50\% content of solid particles, 300-9000 centipoise viscosity and a minimum film-forming temperature (MFFT) of $20^{\circ} \mathrm{C}$.

Table 1

Specifications of coating filler

\begin{tabular}{lcccccc}
\hline Filler & Trade name & Company & $\begin{array}{c}\text { Particle } \\
\text { shape }\end{array}$ & $\begin{array}{c}\text { Particle size } \\
(\mu)\end{array}$ & $\begin{array}{c}\text { Density } \\
\left(\mathrm{kg} / \mathrm{m}^{3}\right)\end{array}$ & $\begin{array}{c}\text { Weight } \\
\text { percentage }\end{array}$ \\
\hline \multirow{2}{*}{ Nanoclay } & $\begin{array}{c}\text { Montmorillonite } \\
\text { K 10 }\end{array}$ & $\begin{array}{c}\text { Sigma- } \\
\text { Aldrich }\end{array}$ & $\begin{array}{c}\text { Plate- } \\
\text { like }\end{array}$ & $\begin{array}{c}10 \%<2 \\
50 \%<6\end{array}$ & $\begin{array}{c}300- \\
90 \%<13\end{array}$ & 370 \\
\hline
\end{tabular}

\begin{abstract}
Methods

\section{Coating method}

Coating formulations were prepared with nanoclay amounts of $0,5,10,15,20$ and $25 \mathrm{wt} \%$, compared to latex. The mixtures formulated according to the specifications provided in Table 2 were mixed at 1500 rpm for 10 minutes. Then, the coating was applied as a thin film on the surface of paper (with a basis weight of about 6 grams per square meter) in a laboratory blade coater. To avoid distortion, the coated paper was placed in an oven for 2 minutes at $80{ }^{\circ} \mathrm{C}$. The amount of coating was determined based on dry weight per unit area of paper.
\end{abstract}

To determine the mechanical and optical properties of the paper, at least 10 repetitions for each sample were performed in accordance with the guidelines of the following standards: tear strength - SCAN $\mathrm{P}_{11}$ :73; burst strength - T403-Om91; tensile strength - T240Om92; stiffness - T240-Om92; optical properties T452-Om98.

\section{$X$-ray diffraction analysis}

X-ray diffraction was performed a Philips Xpert X-ray diffractometer (Netherlands), with cobalt lamp radiation at the wavelength of 1.79 , step of 0.02 degrees, speed of 0.3 degrees per second and $2 \theta$ 
emission angle in the range of 1-9 degrees. Analysis was performed on samples of dimensions of $1 \times 1 \times 10$ $\mathrm{mm}^{3}$, and at device settings of $30 \mathrm{~mA}$ and $40 \mathrm{KV}$.

\section{Scanning electron microscopy}

In order to assess the presence of nanoclay particles on the surface of the paper and fibers, an AIS 2100
Scanning Electron Microscope (SEM), Seron Technology Co., Korea, was used.

\section{Statistical analysis}

Data analysis was performed using SPSS statistical software by variance analysis. Data were classified using the Duncan test at a significance level of $5 \%$.

Table 2

Treatment specifications

\begin{tabular}{ccc}
\hline No & Nanoclay (\%) & Acrylamide latex (\%) \\
\hline 1 & 0 & 0 \\
2 & 5 & 95 \\
3 & 10 & 90 \\
4 & 15 & 85 \\
5 & 20 & 80 \\
6 & 25 & 75 \\
\hline
\end{tabular}

\section{RESULTS AND DISCUSSION}

The tests have shown a significant direct effect of the nanoclay filler in the coating formulation on the air resistance, softness, tensile strength index, stiffness, burst strength index, tear strength index, brightness, opacity and yellowness of the coated samples, at the 5\% significance level. The F-value and significance levels are both shown in Table 3.

\section{Tensile strength index}

The tensile strength is an indicator of the paper's tensile potential durability under tensile stress. The most important factor affecting the tensile strength of paper lies in the quality and number of the bonds created. Thus, increasing the fiber bonds by enhanced refining or wet pressing will increase the paper tensile strength. However, the tensile strength of paper will always be lower than that of the fiber. ${ }^{15}$ Also, the tensile strength in the machine direction is always greater than that in the cross direction, because the fibers are aligned more in the longitudinal direction than in the cross direction. Considering the machine direction (MD), two types of bonds are of interest here, covalent bonding (O-C, C-C) within and between the existing glucose in the cellulose chains, and the hydrogen bonds between the fibers. Generally, there are more covalent bonds in the machine direction and fewer in the cross direction. ${ }^{2}$ The tensile strength evolution of coated printing and writing paper using different nanoclay formulations is shown in Figure 1. As may be noted, the highest and lowest average tensile strength indexes were observed for the sample coated with $10 \%$ nanoclay, with a value of $46.32 \mathrm{Nm} / \mathrm{g}$, and for the one coated with $20 \%$ nanoclay, with a value of $40.60 \mathrm{Nm} / \mathrm{g}$. Moreover, there was a negative correlation between the percentage of nanoclay and paper tensile strength $\left(R^{2}=0.692\right)$.

\section{Stiffness}

The trend of stiffness changes of coated printing and writing paper with different nanoclay formulations is shown in Figure 2. The highest and lowest average stiffness values were observed for the control sample with $0 \%$ nanoclay, with a value of $526.23 \mathrm{KNm}^{-1}$, and for the one coated with $15 \%$ nanoclay, with a value of $478.54 \mathrm{KNm}^{-}$ ${ }^{1}$. Moreover, there was a negative correlation between the percentage of nanoclay and paper stiffness $\left(R^{2}=0.673\right)$. Stiffness is important in some types of papers, especially for copy paper that is supposed passes between rollers. The value of this feature varies depending on the printing manner, while an overly high or low value may lead to problems, such as lack of proper feeding or paper delivery to the further sections. ${ }^{16}$ Comparing the results obtained in this study, it could be concluded that no significant difference was observed under the effect of the nanoclay coating.

\section{Tear strength index}

One of the most significant parameters affecting the tear strength of paper is the fiber length. The evolution trend of tear strength of 
coated printing and writing paper with different nanoclay formulations is shown in Figure 3. The highest and lowest values of the average tear strength index were observed for the sample coated with $10 \%$ nanoclay, with a value of 4.81 $\mathrm{mN} \cdot \mathrm{m}^{2} \mathrm{~g}^{-1}$, and for the one coated with $20 \%$ nanoclay, with a value of $3.91 \mathrm{mN} \cdot \mathrm{m}^{2} \mathrm{~g}^{-1}$, respectively. Moreover, there was a negative correlation between the percentage of nanoclay used in the formulation and the tear strength of paper $\left(\mathrm{R}^{2}=0.532\right)$.

\section{Burst strength index}

The burst strength of paper or its resistance to deformation and rupture is assessed using an expanded rubber membrane and is defined as the hydraulic pressure needed to burst the paper.

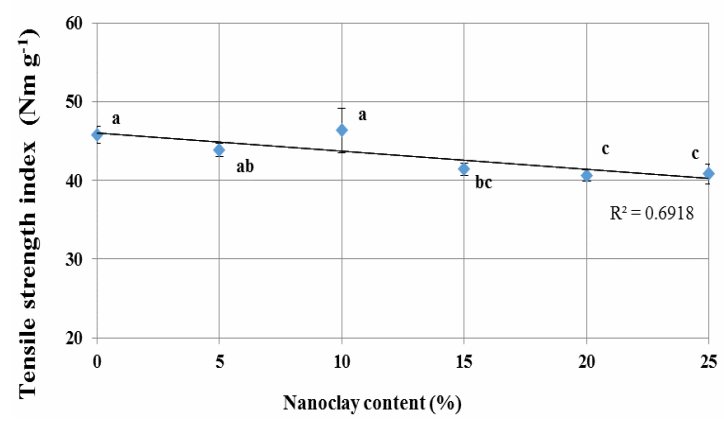

Figure 1: Effect of nanoclay amount on tensile strength of coated paper

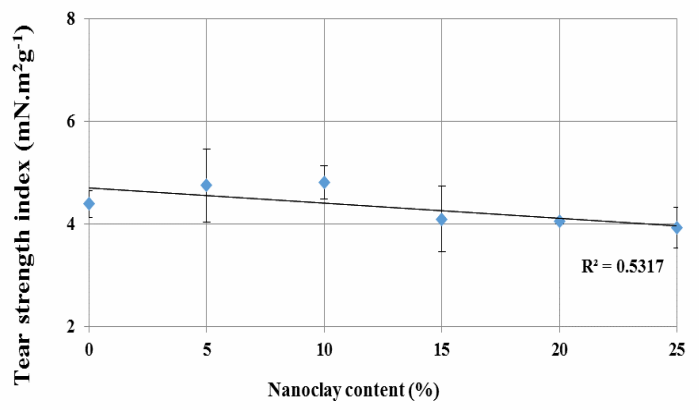

Figure 3: Effect of nanoclay amount on tear strength of coated paper

\section{Softness}

The softness of the coated printing and writing paper as a function of different amounts of nanoclay in the coating formulation is shown in Figure 5. The highest and lowest average softness index values were observed for the sample coated with $10 \%$ nanoclay, with a value of $2493.7 \mu \mathrm{m}$, and for the one coated with $25 \%$ nanoclay, with a
Enhanced fiber length, refining and press pressure contribute to increasing burst strength, while the use of filler materials and inappropriate formation will reduce it. Burst strength is one of the properties that basically depend on fiber length and fiber bonding. ${ }^{17-18}$ The evolution of burst strength as a function of the amount of nanoclay in the coating formulation is shown in Figure 4. The highest and lowest average burst strength values were observed for the sample coated with $5 \%$ nanoclay, with a value of $2.24 \mathrm{kPam}^{2} \mathrm{~g}^{-1}$, and for the one coated with $20 \%$ nanoclay, with a value of $1.6 \mathrm{kPam}^{2} \mathrm{~g}^{-1}$, respectively. Again, there was a negative correlation between the percentage of nanoclay in the coating formulation and the burst strength of paper $\left(\mathrm{R}^{2}=0.31\right)$.

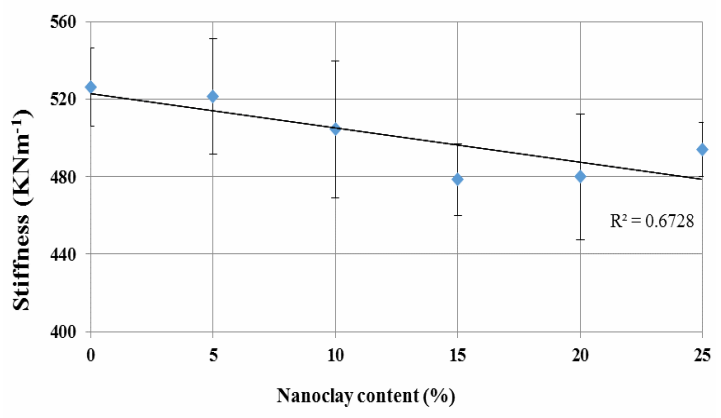

Figure 2: Effect of nanoclay amount on stiffness of coated paper

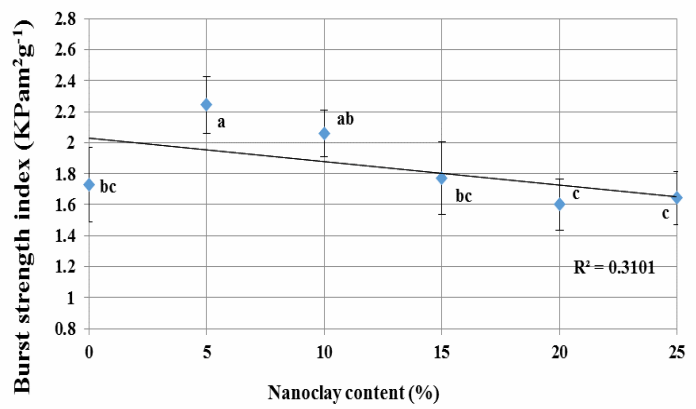

Figure 4: Effect of nanoclay amount on burst strength of coated paper

value of $2393.3 \mu \mathrm{m}$. There was a negative correlation between the percentage of nanoclay used and paper softness $\left(\mathrm{R}^{2}=0.440\right)$. In fact, because of the omission of the lining operation, paper softness was found to be in the lower range. This was an expected effect and the super calendaring operation will certainly improve this property, compared to the control sample. 
Table 3

Variance analysis ( $\mathrm{F}$ and $\mathrm{P}$ values) of the effect of nanoclay coating on paper properties

\begin{tabular}{|c|c|c|c|c|c|c|c|c|c|}
\hline Property & $\begin{array}{c}\text { Tensile } \\
\text { strength } \\
\left(\mathrm{Nm} \cdot \mathrm{g}^{-1}\right)\end{array}$ & $\begin{array}{l}\text { Stiffness } \\
\left(\mathrm{KNm}^{-1}\right)\end{array}$ & $\begin{array}{c}\text { Tear } \\
\text { strength } \\
\left(\mathrm{mN} \cdot \mathrm{m}^{2} \mathrm{~g}^{-1}\right)\end{array}$ & $\begin{array}{c}\text { Burst } \\
\text { strength } \\
\left(\mathrm{kPam}^{2} \mathrm{~g}^{-1)}\right.\end{array}$ & $\begin{array}{c}\text { Softness } \\
(\mu \mathrm{m})\end{array}$ & $\begin{array}{c}\text { Air } \\
\text { resistance } \\
(\mathrm{s})\end{array}$ & $\begin{array}{c}\text { Opacity } \\
(\%)\end{array}$ & $\begin{array}{c}\text { Brightness } \\
(\%)\end{array}$ & $\begin{array}{c}\text { Yellowness } \\
(\%)\end{array}$ \\
\hline CMP & $9.311 *$ & $1.798^{\mathrm{ns}}$ & $2.071^{\mathrm{ns}}$ & $5.186^{*}$ & $0.096^{\mathrm{ns}}$ & $12.196^{*}$ & $6.744 *$ & $162.319 *$ & 153.859* \\
\hline
\end{tabular}

$* 95 \%$ significance level; ${ }^{\text {ns }}$ no significance

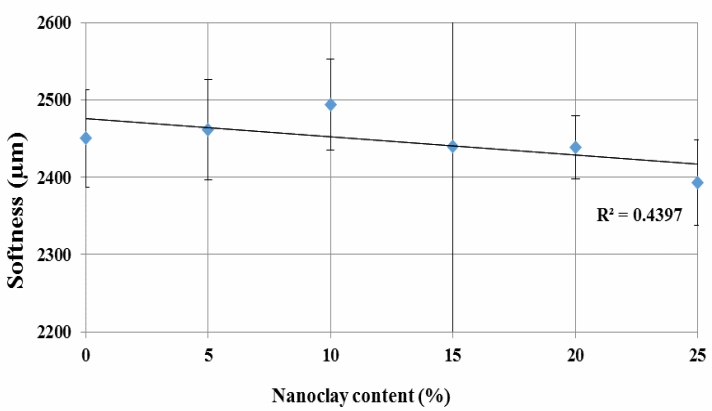

Figure 5: Effect of nanoclay amount on softness of coated paper

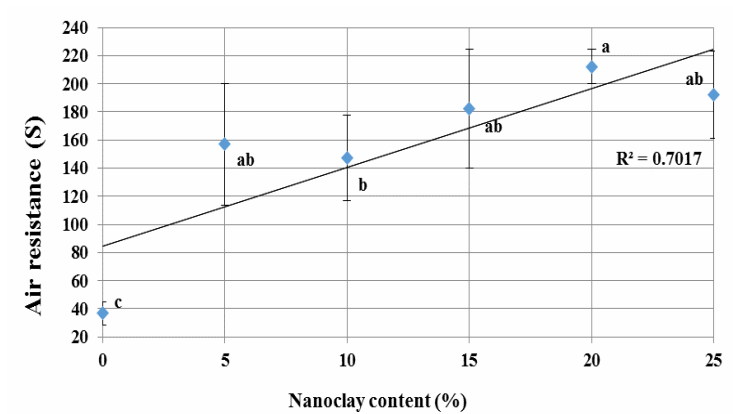

Figure 6: Effect of nanoclay amount on air resistance of coated paper 


\section{Air resistance}

Air resistance tests showed that the application of the coating formulations with increasing amounts of nanoclay, up to a certain level, increased air resistance significantly. The highest air resistance was achieved for the paper coated with $20 \%$ nanoclay. The trend of air resistance of the coated printing and writing paper as a function of different amounts of nanoclay in the coating formulation is shown in Figure 6. The lowest and highest averages of air resistance were observed for the control sample with $0 \%$ nanoclay, with a value of $36.67 \mathrm{~s}$, and the sample coated with $20 \%$ nanoclay, with a value of 212.33 s. Moreover, there was a positive correlation between the percentage of nanoclay and paper air resistance $\left(\mathrm{R}^{2}=0.702\right)$.

\section{Opacity}

The evolution of opacity upon addition of different amounts of nanoclay into the coating formulation is illustrated in Figure 7. As may be noted, the lowest and highest averages of opacity were observed for the control sample with $0 \%$ nanoclay, with a value of $89.46 \%$, and for the one

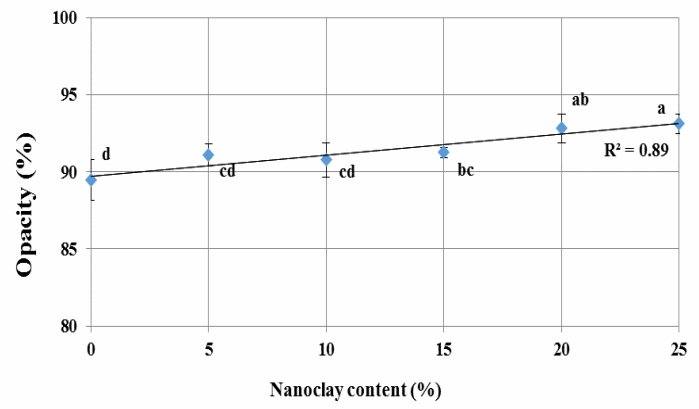

Figure 7: Effect of nanoclay amount on opacity of coated paper treated with $25 \%$ nanoclay, with a value of $93.11 \%$, respectively. There was a positive correlation between the percentage of nanoclay used and paper opacity $\left(\mathrm{R}^{2}=0.89\right)$. Upon increasing the amount of nanoclay in the coating formulation, the opacity of paper increases. This result was in line with the findings of Hagemeyer. ${ }^{16}$ Filler particles increase light scattering and thus enhance the opacity of paper. $^{20,21}$ Our results regarding opacity are in agreement with those reported in earlier studies. ${ }^{22}$

\section{Brightness}

The trend of brightness changes of coated printing and writing paper upon the application of coating with different amounts of nanoclay is shown in Figure 8. As can be noted, the lowest and highest averages of brightness were observed for the control sample with $0 \%$ nanoclay, with a value of $74.35 \%$, and for the one coated with $25 \%$ nanoclay, with a value of $65.59 \%$, respectively. There was a negative correlation between the percentage of nanoclay used and paper brightness $\left(R^{2}=0.935\right)$.

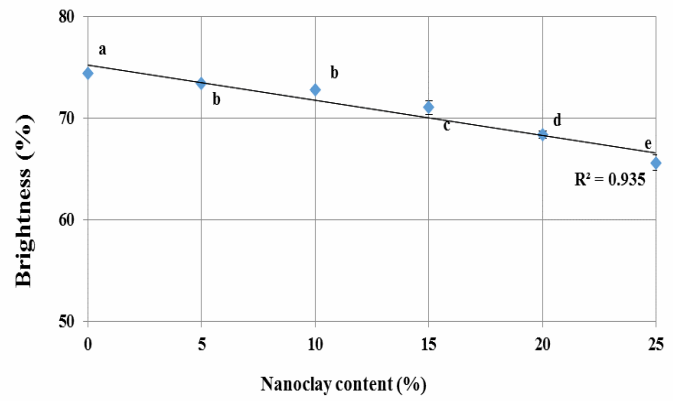

Figure 8: Effect of nanoclay amount on brightness of coated paper

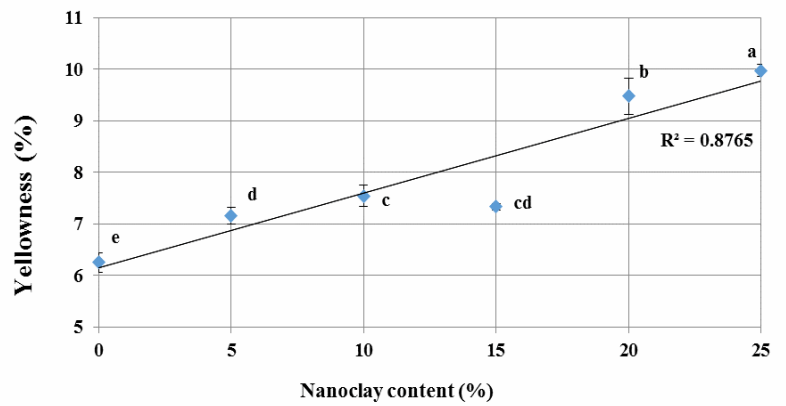

Figure 9: Effect of nanoclay amount on brightness of coated paper

\section{Yellowness}

The evolution of yellowness upon addition of different amounts of nanoclay into the coating formulation is shown in Figure 9. As can be noticed, the lowest and highest averages of yellowness were observed for the control sample with $0 \%$ nanoclay, with a value of $6.25 \%$, and for the sample treated by $25 \%$ nanoclay, with a value 
of $9.97 \%$, respectively. Moreover, there was a positive correlation between the percentage of nanoclay used and paper yellowness $\left(\mathrm{R}^{2}=0.877\right)$. Brightness decreases and yellowness increases upon increasing the nanoclay amount in the formulation, and this outcome was caused by the optical properties of the nanoclay raw material. Obviously, if an increase in brightness is necessary, polymer materials with high brightness or titanium dioxide up to $10 \%$ can be used in the coating formulation. ${ }^{1}$

\section{Microscopic studies of paper structure (SEM)}

Figure 10 (A to F) illustrates the surface of the printing paper coated with $0,5,10,15,20$ and $25 \%$ nanoclay. As it can be seen in the figures, after applying the coating formulations, the surface of the fibers is substantially covered, so when $25 \%$ of nanoclay was used, the paper surface was fully coated and very few pores can be seen. In fact, the addition of the mineral clay improved the coverage of the paper surface and, by the blade coating technique, a relatively smooth surface of the coating can be achieved on this type of paper.

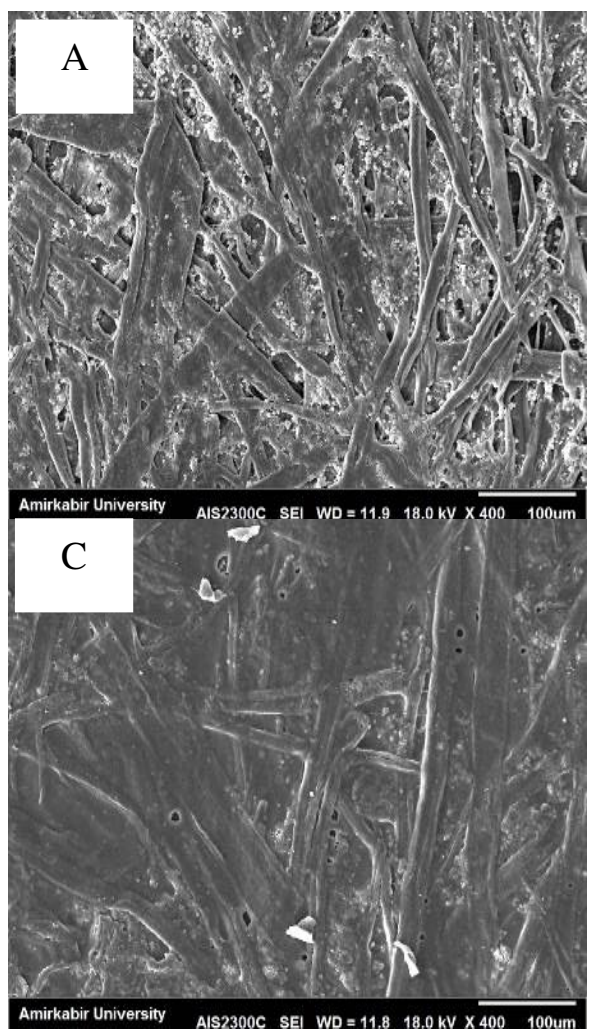

\section{Structural study by X-ray diffraction (XRD)}

$\mathrm{X}$-ray diffraction spectra of the paper coated with nanoclay and acrylic resin in different percentages were obtained at angles from 2 to 11 degrees. As can be observed in Figure 11, the morphological structures are of the intercalated type, and as the amount of nanoclay in the composition increased from 0 to $25 \mathrm{wt} \%$, the $2 \theta$ peak angle also increased. According to Figure 11 , the X-ray diffraction peak of the nanoclay (modified K10) is located at an angle of $2 \theta=$ $7.03^{\circ}$ and a d-spacing of $14.58 \AA$. When increasing the amount of nanoclay to $5 \%$ by weight, the X-ray diffraction peak shifted to $2 \theta=$ $8.01^{\circ}$. At this angle, the $\mathrm{d}$-spacing is $\mathrm{d}=12.81 \AA$. Increasing the nanoclay amount up to $10 \%$ by weight pushes the $\mathrm{X}$-ray peak again forward and d-spacing decreases $\left(2 \theta=8.03^{\circ}\right.$ and $d=12.77 \AA$ ). The treatment with the formulation with $15 \%$ nanoclay by weight shifts the X-ray diffraction peak to a higher angle $2 \theta=8.09^{\circ}$. At this angle, $\mathrm{d}$-spacing is $\mathrm{d}=12.68 \AA$. Increasing the nanoclay amount to $20 \%$ by weight leads to $2 \theta=8.15^{\circ}$ and $\mathrm{d}=12.58 \AA$. Further increasing the amount of nanoclay to $25 \mathrm{wt} \%$ determines a higher increase of the $2 \theta$ peak angle.

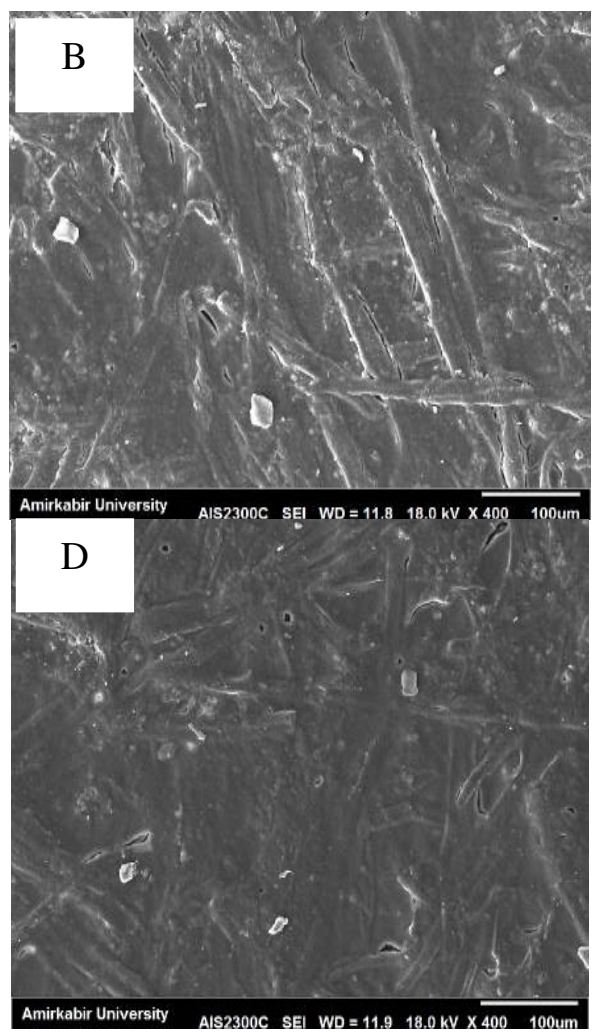



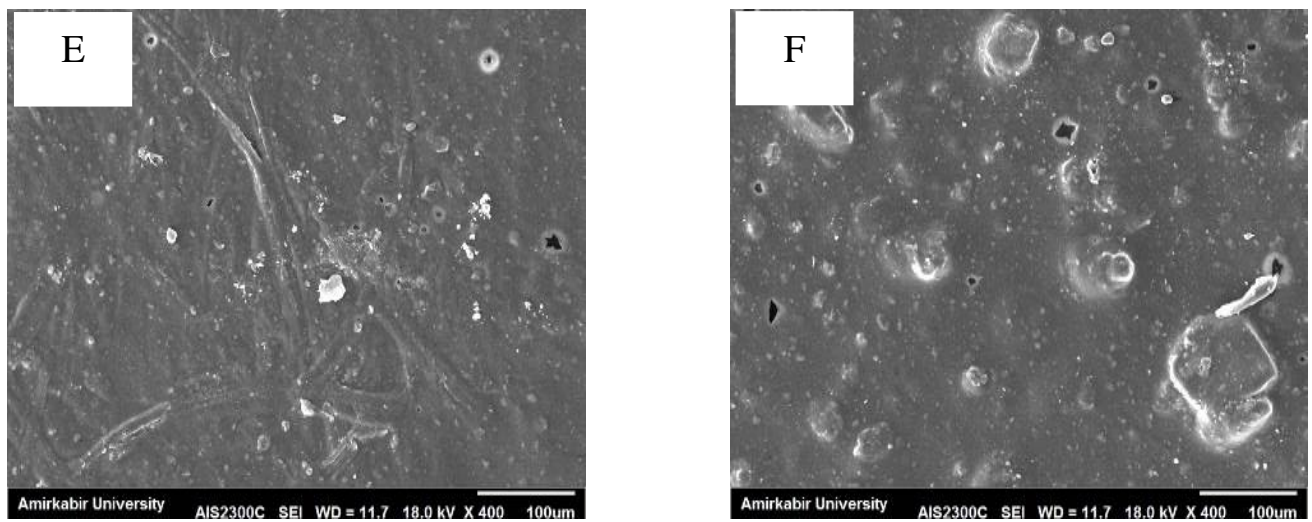

Figure 10: SEM images of paper coated with A) $0 \%$ nanoclay, B) 5\% nanoclay, C) $10 \%$ nanoclay,

D) $15 \%$ nanoclay, E) $20 \%$ nanoclay, F) $25 \%$ nanoclay

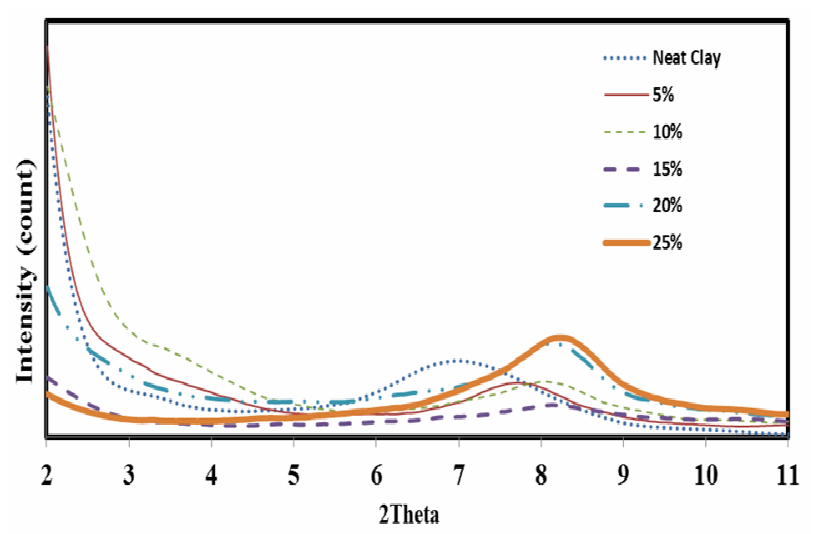

Figure 11: X-ray spectra of paper coated with 5, 10, 15, 20 and 25\% nanoclay

According to Figure 11, the X-ray diffraction peak of nanoclay is located at a $2 \theta$ angle $=8.17^{\circ}$ and d-spacing of $12.55 \AA$. Since the peak of the clay crystalline area has not disappeared, but has increased the $2 \theta$ angle, the interplanar distance has declined (according to Bragg's equation). This indicated the intercalated structure of the developed material.

\section{CONCLUSION}

The present investigation allowed drawing the following conclusions. Increasing the amount of nanoclay in the coating formulation up to $25 \%$ led to increased air resistance, opacity and yellowness of the coated paper samples, compared to the control samples, by 423.6, 4.1 and 59.5\%, respectively. Also, coating the paper with a higher amount of nanoclay (up to 25\%) resulted in lower tensile, tear and burst strength by 12.2, 12 and $5.5 \%$, respectively, as well as in lower stiffness and smoothness, but higher opacity by $6.5,2.2$ and $13.4 \%$, respectively, compared to the control samples. XRD analysis revealed that an intercalation structure was created, while electron microscopy results showed an enhanced coating of the paper surface with increasing nanoclay percentage in the coating formulation.

ACKNOWLEDGMENTS: This article is derived from the Master of Science thesis of Hushang Ghanbari (Islamic Azad University, Savadkooh, Iran). The authors appreciate the support received from the Islamic Azad University, Savadkooh, Mazandaran, Iran.

\section{REFERENCES}

1 E. Lehtinen, "Pigment Coating and Surface Sizing of Paper", Papermaking Science and Technology, Book 11, Helsinki University of Technology, 2000, pp. 810.

2 Y. Hamzeh and A. Rostampour, "Principals of Papermaking Chemistry", University of Tehran Press, Tehran, 2008, pp. 424.

3 S. C. Tjong, Mater. Sci. Eng. R. Rep., 53, 73 (2006), https://doi.org/10.1016/j.mser.2006.06.001 
4 M. F. Hossen, S. Hamdan, M. R. Rahman, M. S. Islam, F. K. Liew et al., Measurement, 90, 404 (2016), https://doi.org/10.1016/j.measurement.2016.05.006

5 A. Tavasoli and A. Samariha, Cellulose Chem. Technol., $\quad 51, \quad 513 \quad$ (2017), http://www.cellulosechemtechnol.ro/pdf/CCT56(2017)/p.513-520.pdf

6 S. Mirmehdi, P. R. G. Hein, C. I. G. de Luca Sarantópoulos, M. V. Dias and G. H. D. Tonoli, Food. $\begin{array}{lllll}\text { Packag. } & \text { Shelf., } & \mathbf{1 5}, & 87 & \text { (2018), }\end{array}$ https://doi.org/10.1016/j.fpsl.2017.11.007

7 D. W. Donigian, P. C. Wernett, M. G. McFadden and J. J. McKay, Tappi J., 82, 175 (1999).

8 A. Hladnik and T. Muck, Dyes Pigments, 54, 253 (2002), https://doi.org/10.1016/S0143-7208(02)000505

H. Lee, M. K. Joyce, P. D. Fleming and J. E. Cawthorne, Tappi J., 4, 11 (2005).

10 H. Nilsson and A. Fogden, Appita J., 61, 120 (2008).

11 K. Vikman and T. Vuorinen, Nord. Pulp Paper Res., 19, 481 (2004), DOI: 10.3183/NPPRJ-2004-1904-p481-488

12 M. Taghavi, S. M. Kassiriha, A. A. Sarabi and H. Nazokdast, J. Color. Sci. Tech., 5, 129 (2011).

13 R. W. Wygant, R. J. Pruett and C. Y. Chen, in Procs. Coating Fundamentals Symposium Proceedings, Tappi Press, Atlanta, GA, USA, 1995, pp. 85-91.
14 J. E. Kasmani, S. Mahdavi, A. Samariha and M. Nemati, BioResources, 8, $6472 \quad$ (2013), https://bioresources.cnr.ncsu.edu/resources/mechanical -strength-and-optical-properties-of-lwc-woodcontaining-paper/

15 E. Afra, "Properties of Paper: An Introduction", Aeeizh Press, Tehran, 2006, pp. 186.

16 S. A. Mirshokraei and H. Sadeghifar, "The Chemistry of Paper", Aeeizh Press, 2007, pp. 326.

17 G. Asadpour, A. Ghasemian, A. Saraeian and M. Ghaffari, in Procs. First Iranian Conference on Supplying Raw Materials and Development of Wood and Paper Industries, Gorgan, Iran, 2008.

18 I. Akbarpour and H. Resalati, Iranian Journal of Wood and Paper Industries, 2, 1 (2011).

19 R. Hagemeyer, Tappi J., 78, 98 (1997).

20 A. Nazeri, Iran. Wood Paper Sci., 22, 29 (2007).

21 M. A. Hubbe and R. A. Gill, in Procs. Spring Tech. Conference, TAPPI Press, Atlanta, 2004, pp. 141-150.

22 D. Song, C. Dong, A. Ragauskas and Y. Deng, in Procs. Tappi Conference, June 9, 2009. 